\title{
Metalheads: The Influence of Personality and Individual Differences on Preference for Heavy Metal
}

\author{
Viren Swami \\ University of Westminster and HELP University College
}

\author{
Fiona Malpass, David Havard, Karis Benford, \\ Ana Costescu, Angeliki Sofitiki, and Donna Taylor \\ University of Westminster
}

\begin{abstract}
Previous studies have reported reliable associations between personality and music preferences, but have tended to rely on cross-genre preferences at the expense of preferences within a single subgenre. We sought to overcome this limitation by examining associations between individual differences and preferences for a specific subgenre of music, namely, contemporary heavy metal. A total of 414 individuals from Britain were presented with clips of 10 tracks of contemporary heavy metal and asked to rate each for liking. Participants also completed measures of the Big Five personality traits, attitudes toward authority, self-esteem, need for uniqueness, and religiosity. A multiple regression showed that stronger composite preference for the heavy metal tracks was associated with higher Openness to Experience, more negative attitudes toward authority, lower self-esteem, greater need for uniqueness, and lower religiosity. In addition, men showed a significantly stronger preference for the tracks than women $(d=0.54)$. These results are discussed in terms of the psychological needs that contemporary heavy metal fills for some individuals.
\end{abstract}

Keywords: heavy metal, personality, openness to experience, attitudes toward authority, music

Although there is now a thriving body of work examining the factors that shape aesthetic preferences, this research has focused heavily on different forms of visual art (Swami \& Furnham, in press). By contrast, scholars have paid other aesthetic domainssuch as literature, film, and fashion-much less attention, which is notable because domain type may be an important moderator of preferences. For example, it is thought that music is one domain in which preferences are idiosyncratic, irrespective of one's appreciation of other artistic domains (North \& Hargreaves, 1999; ter Bogt, Raaijmakers, Vollebergh, van Well, \& Sikkema, 2003), and that music preferences form an important part of one's identity, especially in adolescence and young adulthood (Rentfrow \& Gosling, 2006, 2007; Selfhout, Branje, ter Bogt, \& Meeus, 2009).

Although the importance of music in everyday life is widely acknowledged (North, Hargreaves, \& O'Neill, 2000; Schwartz \& Fouts, 2003), the factors that shape music preferences could be better understood. In the $1980 \mathrm{~s}$, media psychologists began to

This article was published Online First October 14, 2013.

Viren Swami, Department of Psychology, University of Westminster, London, United Kingdom, and Department of Psychology, HELP University College, Kuala Lumpur, Malaysia; Fiona Malpass, David Havard, Karis Benford, Ana Costescu, Angeliki Sofitiki, and Donna Taylor, Department of Psychology, University of Westminster, London, United Kingdom.

Correspondence concerning this article should be addressed to Viren Swami, Department of Psychology, University of Westminster, 309 Regent Street, London W1B 2UW, United Kingdom. E-mail: v.swami@ westminster.ac.uk emphasize the importance of considering motives for cultural consumption (Rosengren, Wenner, \& Palmgreen, 1985). From this perspective, it was suggested that individuals prefer and select certain types of music because they have personality traits that the music satisfies (Arnett, 1995; Arnett, Larson, \& Offer, 1995; Larson, 1995). For example, individuals who have a desire for intellectual stimulation and novel aesthetic experiences are expected to show a preference for complex forms of music. In addition, music selections may also fulfill physiologically based needs (Eysenck, 1990; Zuckerman, 1979), such as when extraverts select music that raises their low cortical arousal (Berlyne, 1960).

This work led to a revival of interest in the aesthetics of music from a differential perspective (e.g., Dollinger, 1993; McCown, Keiser, Mulhearn, \& Williamson, 1997). It is now widely acknowledged that there are reliable associations between music preferences and personality (Pearson \& Dollinger, 2002; Rentfrow \& McDonald, 2009; Schwartz \& Fouts, 2003), with the latter commonly being operationalized using the Big Five traits. Scholars working from this perspective hypothesize that personality traits influence preferences for music, both in terms of established preferences for particular genres and pieces of music (Rentfrow \& Gosling, 2006; Rentfrow \& McDonald, 2009), as well as in the short term (e.g., in response to hearing novel or unfamiliar music in laboratory settings; Hunter \& Schellenberg, 2011; Ladinig \& Schellenberg, 2012).

In summarizing established relationships between musical dimensions and personality traits, Rentfrow and Gosling (2003) reported that a preference for reflective and complex music (defined by the blues, jazz, classical, and folk music) and intense and rebellious music (rock, alternative, and heavy metal) was posi- 
tively associated with the Big Five trait of Openness to Experience. A preference for upbeat and conventional music (country, soundtrack, religious, and pop music) was positively related to Extraversion, Agreeableness, and Conscientiousness, but negatively related to Openness. Finally, a preference for energetic and rhythmic music (rap, hip-hop, soul and funk, and electronica and dance music) was positively correlated with Extraversion and Agreeableness. These associations were generally supported in a more recent, longitudinal study with Dutch adolescents (Delsing, ter Bogt, Engels, \& Meeus, 2008).

Although this research is important, one drawback of these studies is that they have examined cross-genre preferences at the expense of preferences within a single genre of music. That is, although it is important to examine the way individual differences affect preferences for musical genres that differ across multiple dimensions, this method possibly obscures unique associations when the focus is on musical pieces that are defined by the same artistic style (cf. Swami, Pietschnig, Stieger, Nader, \& Voracek, 2012; Swami, Stieger, Pietschnig, \& Voracek, 2010). To overcome this dearth in the literature, the present study examined associations between individual differences and preference for contemporary heavy metal, a subgenre of rock music with historical roots in blues and psychedelic rock (Weinstein, 2000).

Relative to early heavy metal, contemporary metal (e.g., metalcore, extreme metal, thrash metal)-also sometimes called the New Wave of Heavy Metal (Sharpe-Young, 2005)—is specifically characterized by heavy guitar riffs, double-bass drumming, breakdowns (slow, intense passages that are conducive to moshing, i.e., a style of dance in which participants push or slam into each other), and overall loudness (Dee, 2009; Sharpe-Young, 2005; Wagner, 2010). In addition, the vocalizing technique in contemporary metal is generally unpitched vocals (e.g., shouting, shrieking, and growling), although some bands combine this with clean, melodic vocals (Wallach, Berger, \& Greene, 2011). Rhythmically, contemporary heavy metal songs are emphatic, with highly complex rhythmic phrases (Waksman, 2009) and a wide range of tempos tending toward the extremes (e.g., slow-ballad tempos have quarter notes of 60 beats per min, whereas blast-beat tempos have quarter notes of about 350 beats per min; Sharpe-Young, 2005, 2007). It is these qualities of contemporary heavy metal that distinguish it from earlier incarnations and make it interesting from a scholarly point of view.

To be sure, a small body of work has investigated the aesthetics of heavy metal music or its fans (Baugh, 1993). For example, in early sociological work, Arnett (1993, 1996) highlighted a "subculture of alienation" among heavy metal fans, which, in turn, was thought to translate into an opposition to authority and a construction of the self as an outsider in relation to mainstream society (Brown, 1995; Weinstein, 2000). It has also been suggested that heavy metal may serve a "purgative function, dissipating accumulated anger and frustration" with established authority or mainstream society (Arnett, 1991, p. 76) and that its cathartic potential may help promote more positive self-evaluations among fans (Henry \& Caldwell, 2007). Moreover, through the consumption of heavy metal music and related products, fans may form and maintain a sense of individual and collective uniqueness (Snell \& Hodgetts, 2007).

Some studies have also examined associations between individual difference traits and a preference for rock or metal music (e.g.,
Shafron \& Karno, 2013). One study presented undergraduates with video recordings of hard-rock music and reported that viewing enjoyment was positively associated with psychoticism and rebelliousness (Robinson, Weaver, \& Zillman, 1996). The same study also indicated that men were more likely than women to enjoy the recordings, which is consistent with suggestions that rock and metal can be instrumental in the construction of masculinity (Fast, 2005; Weinstein, 2009). Fans of heavy metal also appear to be less religious than nongenre fans (Arnett, 1991), and it has also been suggested that heavy metal fans are anticulture in the sense that they oppose hegemonic mainstream music and culture (Rana, 2008). Finally, stereotypic depictions of metal fans suggest that they are violent and antisocial (Wright, 2000), but empirical evidence is mixed: One study reported no significant association between a preference for heavy metal and behavioral problems (Epstein, Pratto, \& Skipper, 1990), whereas others have reported that heavy metal listeners are more violent (Hansen \& Hansen, 1991) and are more likely to engage in risky behaviors such as using drugs and stealing (Klein et al., 1993; Weisskirch \& Murphy, 2004).

The present study sought to build on this work by examining the influence of individual difference traits on preference for contemporary heavy metal, operationalized by computing a composite index of liking for 10 heavy metal tracks by contemporary bands that fit the New Wave tag (Sharpe-Young, 2005). In this way, we were able to measure preference for songs that conform to genrespecific characteristics, as described earlier. In addition, we measured participants' Big Five personality traits, with the expectation that preference for heavy metal would be positively associated with Openness to Experience. This is based on the previous finding that a preference for heavy metal was significantly associated with Openness (Delsing et al., 2008; Rentfrow \& Gosling, 2003). By contrast, we did not expect significant associations with other Big Five traits, although we did include these for preliminary analyses.

In addition to the Big Five traits and based on the review here, we also included measures of need for uniqueness, self-esteem, attitudes toward authority, and religiosity. The former variable refers to a desire to create and maintain a sense of uniqueness, particularly in social settings (Lynn \& Snyder, 2002). Given discussions of heavy metal as facilitating a subculture of alienation and a construction of the self as an outsider, we hypothesized that a preference for heavy metal would be significantly associated with higher need for uniqueness. Self-esteem, on the other hand, refers to an overall emotional evaluation of one's worth (Mruk, 2006), and we expected a negative association between self-esteem and a preference for heavy metal. This was based on the possibility that the cathartic potential of heavy metal is sought by individuals who have low self-esteem. Finally, we hypothesized that a preference for heavy metal would be associated with more negative attitudes toward authority and lower religiosity, which is consistent with Arnett's (1991) work.

\section{Method}

\section{Participants}

The participants of this study were 219 women and 195 men ranging in age from 18 to 57 years $(M=25.30, S D=9.31)$. The majority of participants were of British White descent $(88.4 \%)$, 
and the remainder were Asian (7.2\%), African Caribbean (1.4\%), or other ancestry (2.9\%). In terms of educational qualifications, $43.4 \%$ had completed secondary education, $43.5 \%$ were still in full-time (university) education, $10.1 \%$ had an undergraduate degree, and $3.0 \%$ had a postgraduate degree.

\section{Materials}

Heavy metal tracks. We initially selected 10 tracks by 10 heavy metal bands that fit the New Wave tag (see Sharpe-Young, 2005). The final list consisted of three heavy metal bands, two metalcore bands, two progressive metal bands, one power metal band, one thrash metal band, and one extreme metal band (see Appendix for band names, tracks, albums the tracks were taken from, and year the tracks were released in the United Kingdom). All bands that were included in the present study had a minimum of four members (a drummer, a bassist, a rhythm guitarist, and a vocalist), and four of the tracked included the use of musical keyboards or synthesizers, as in the norm for the band in question. For each band, we selected one exemplar track, from which we then extracted a 60-s clip, always from the middle of the track. Participants were presented with these clips and asked to rate each for personal preference on a 7-point scale $(1=$ extreme dislike, $7=$ extreme like $)$. Treatment of these data is discussed in the Results section.

Big Five personality traits. We measured the Big Five personality traits using the Mini International Personality Item Pool (Mini-IPIP; Donnellan, Oswald, Baird, \& Lucas, 2006), a 20-item short form of the full IPIP measure (Goldberg, 1999). Participants were asked to rate the extent to which a series of statements accurately described themselves on a 5-point Likert-type scale $(1=$ very inaccurate, $5=$ very accurate $)$. Subscale scores for each of the Big Five traits were computed as the mean of four items associated with each factor, respectively, following reverse coding of some items. The Mini-IPIP has been shown to have good internal consistency, good patterns of convergent and discriminant validity, similar coverage of facets as other broad Big Five measures, and good test-retest reliability up to several months (Donnellan et al., 2006). In the present study, internal consistency coefficients (Cronbach's alpha) for all subscales were $>.63$, which is consistent with previous work (Donnellan et al., 2006). Specific coefficients were as follows: Extraversion, .68; Ideas/ Openness to Experience, .70; Agreeableness, .65; Conscientiousness, .65; and Neuroticism, .64.

Need for uniqueness. Need for uniqueness was measured using the 32-item Uniqueness Scale (Snyder \& Fromkin, 1977), which assessed an individual's desire to create and maintain a sense of uniqueness, especially in public and social settings. Participants were asked to rate each item on the scale on a 5-point Likert-type scale ( 1 = strongly disagree, 5 = strongly agree $)$, and an overall score was computed as the mean of all items, following reverse coding of some items. Higher scores on this scale reflect greater need for uniqueness. Snyder and Fromkin (1977) reported that the scale has good patterns of validity and good test-retest reliability up to 4 months. In the present study, Cronbach's alpha for this scale was .82 .

Self-esteem. To measure self-esteem, we used Rosenberg's (1965) Self-Esteem Scale, one of the most widely used measures of an individual's feelings of self-worth. The scale consists of 10 items that are rated on a 4-point Likert-type scale $(1=$ strongly disagree, $4=$ strongly agree). Several items were reversed coded prior to analysis and an overall score was computed as the mean of all 10 items. Higher scores on this scale reflect greater self-esteem. Scores on this measure have been shown to have good internal consistency and good patterns of validity (Whiteside-Mansell \& Corwyn, 2003). In the present study, this scale had good internal consistency (Cronbach's alpha $=.89$ ).

Attitudes toward authority. Participants' evaluations of authority were measured using Reicher and Emler's (1985) Attitudes to Authority Scale, which was adapted to exclude adolescenttargeted items referring to the fairness of school rules (Swami, Chamorro-Premuzic, \& Furnham, 2010). The adapted measure consists of 10 items that tap attitudes about institutional authority, bias by those in authority, and the absolute priority of rules. All items were rated on a 5-point Likert-type scale $(1=$ strongly disagree, 5 = strongly agree), and some items were reverse coded prior to analyses. An overall score was computed as the mean of all items, with higher scores indicating more negative attitudes toward institutional authority. This adapted measure has been shown to have adequate internal consistency and patterns of validity (Swami, 2012; Swami, Chamorro-Premuzic, et al., 2010). In the present study, Cronbach's alpha for this scale was .76.

Religiosity. Participants' religiosity was measured using a single-item measure of intrinsic religiosity $(1=$ not at all religious, $7=$ very religious). The use of a single item is limiting in terms of breadth; nevertheless, single-item measures of religiosity have been shown to have good validity among community samples (e.g., Abdel-Khalek, 2007).

Demographics. Participants were asked to provide their demographic details, including gender, age, ethnicity, and highest educational qualifications.

\section{Procedures}

Ethical approval for this study was obtained from the relevant university ethics committee. Data collection for this study was conducted online using an opportunistic sampling strategy. The researchers invited potential participants to complete a survey on music preferences via their contacts on a social networking site (i.e., Facebook). A total of 664 individuals opened the first page of the survey and 414 provided complete responses on the whole survey. The first page of the online survey presented participants with brief information about the research project and allowed them to provide informed consent. The next page informed participants that they would be presented with several clips of music, which they would be asked to rate for personal preference. Participants were also given instructions at this stage to turn the volume on their computers to a comfortable level and to listen to the clips in their entirety before making their ratings. On the next 10 pages, participants were presented with the selected tracks, which loaded automatically once the page had been accessed, and were able to provide their ratings. The 10 tracks were presented in a random order for each participant. Subsequent pages of the survey presented measures of the Big Five, need for uniqueness, self-esteem, attitudes toward authority, religiosity, and demographic, in this predefined order. The final page of the survey presented participants with debriefing information, including contact details of the corresponding author. All participants took part on a voluntary basis and were not remunerated for participation. 


\section{Results}

\section{Factor Analysis}

We initially subjected preference ratings of the 10 music clips to principle-axis exploratory factor analysis using the total sample. Bartlett's test of sphericity, $\chi^{2}(45)=3429.43, p<.001$, and the KaiserMeyer-Olkin $(\mathrm{KMO})$ measure of sampling adequacy $(\mathrm{KMO}=.89)$ showed that the 10 items had adequate common variance for factor analysis. We therefore computed a factor analysis using quartimax rotation because we expected the emergence of a single, general factor. Examination of the results indicated that only one factor had an eigenvalue $>1.0(\lambda=5.85 ; 54.5 \%$ of the variance explained $)$. All 10 items loaded on to this first factor with loadings $\geq .66$, which far exceed Kline's (1986) recommended cutoff of .40. These results indicate that it was acceptable to compute a composite index of preference for the music clips, which we did by taking the mean of all 10 ratings. The internal consistency coefficient of this measure was very good (Cronbach's alpha $=.94)$.

\section{Further Analyses}

Descriptive statistics for all variables included in the present study are reported in Table 1. Preliminary examination of the data indicated that men $(M=3.65, S D=1.44)$ showed a stronger preference for the clips than women $(M=1.94, S D=1.24)$. An independent samples $t$ test indicated that this difference was significant, $t(413)=5.44, p<.001, d=0.54$. There were no significant correlations between preference for the clips and participant age, $r=.05, p=.360$, or educational qualifications, $r=$ $.05, p=.358$, so these variables were not analyzed further. In a similar vein, there were no significant differences in preference for the clips between White and non-White participants, $t(412)=$ $1.61, p=.109, d=0.16$. We next computed bivariate correlations between the composite preference score and participants' score on measures of the Big Five, need for uniqueness, self-esteem, attitudes toward authority, and religiosity. As shown in Table 1, stronger preference for the heavy metal clips was significantly correlated with higher Openness, more negative attitudes toward authority, greater need for uniqueness, lower self-esteem, and lower religiosity.
We next computed a multiple linear regression (enter method) with the composite preference score as the criterion variable and all remaining variables as predictors. Results showed that the regression was significant, $F(9,413)=11.59, p<.001$, adjusted $R^{2}=.19$. Of the variables entered into the model, Openness emerged as the strongest predictor $(\beta=.25, t=5.48, p<.001)$. In addition, attitudes toward authority $(\beta=.24, t=5.06, p<$ $.001)$, self-esteem $(\beta=-.22, t=-3.83, p<.001)$, need for uniqueness $(\beta=.14, t=2.96, p=.003)$, and religiosity $(\beta=$ $-.13, t=2.56, p=.011)$ also emerged as significant predictors. None of the other Big Five traits emerged as significant predictors in this analysis $(\beta \leq .06, t \leq 1.21, p \geq .225)$.

\section{Discussion}

In the past decade, it has become clear that there are reliable associations between music preferences and individual psychological differences (Delsing et al., 2008; Rentfrow \& Gosling, 2003; Rentfrow \& McDonald, 2009). However, this research has tended to focus on broad, nonexclusive genres of music at the expense of a focus on singular, stylized genres. The present study sought to overcome this dearth in the literature by focusing on preferences for a specific subgenre, namely, contemporary heavy metal. Broadly speaking, our results support the assumption that personality and individual differences are associated with preferences for particular music genres (Rentfrow \& McDonald, 2009). Our results also build on earlier work suggesting that heavy metal fans may have profiles that distinguish them from fans of other musical genres (Arnett, 1991, 1993, 1996; Robinson et al., 1996; Weinstein, 2000).

In terms of the Big Five personality traits, our results confirm previous reports that Openness is associated with a preference for rock and heavy metal (Rentfrow \& Gosling, 2003), including nonmainstream subgenres (Delsing et al., 2008). In explanation, it has been suggested that individuals who score highly on Openness show a preference for the intensity, variety, complexity, and unconventionality of heavy metal (Rentfrow \& Gosling, 2003; Rentfrow \& McDonald, 2009). Delsing et al. (2008) further postulated that individuals who are open-minded and who seek novel experiences may become disinterested in mainstream or conventional musical forms as they grow older. This, in turn, may lead them to seek out musical genres

Table 1

Interscale Correlations Between, and Descriptive Statistics For, All Variables Included in the Present Study

\begin{tabular}{|c|c|c|c|c|c|c|c|c|c|c|}
\hline & (1) & (2) & (3) & (4) & (5) & (6) & (7) & (8) & (9) & (10) \\
\hline (1) Preference for heavy metal & & .04 & .01 & -.01 & $.37^{* *}$ & -.03 & $.18^{* * *}$ & $-.14^{*}$ & $.27^{* * *}$ & $-.13^{*}$ \\
\hline (2) Extraversion & & & .06 & $-.13^{*}$ & -.07 & -.05 & $.18^{* *}$ & $.35^{* *}$ & $-.11^{*}$ & $-.11^{*}$ \\
\hline (3) Agreeableness & & & & $.20^{\text {** }}$ & $-.14^{*}$ & $.31^{* *}$ & .07 & .02 & .08 & .02 \\
\hline (4) Conscientiousness & & & & & $-.17^{*}$ & .08 & -.06 & $.34^{* *}$ & -.03 & .06 \\
\hline (5) Ideas/Openness & & & & & & $.20^{* *}$ & $-.16^{*}$ & $-.19^{\text {*** }}$ & -.05 & -.01 \\
\hline (6) Neuroticism & & & & & & & -.09 & -.02 & $.19^{* * *}$ & $-.13^{*}$ \\
\hline (7) Need for uniqueness & & & & & & & & -.07 & $-.16^{* *}$ & -.08 \\
\hline (8) Self-esteem & & & & & & & & & .08 & $.16^{* * *}$ \\
\hline (9) Attitudes to authority & & & & & & & & & & $-.10^{*}$ \\
\hline \multicolumn{11}{|l|}{ (10) Religiosity } \\
\hline$M$ & 3.27 & 3.19 & 4.03 & 3.37 & 2.86 & 4.03 & 2.90 & 2.90 & 3.11 & 2.06 \\
\hline$S D$ & 1.38 & 0.92 & 0.67 & 0.72 & 0.94 & 0.75 & 0.37 & 0.59 & 0.38 & 1.62 \\
\hline
\end{tabular}

Note. $\quad N=414$.

${ }^{*} p<.05, \quad{ }^{* *} p<.001$. 
that are unconventional by the standards of mainstream cultures, such as contemporary heavy metal.

Of course, this is not to suggest that individuals who are high in Openness will necessarily be drawn to heavy metal. Rather, it seems more likely that they will be drawn to forms of music that are intense, engaging, and challenging (Rentfrow, Goldberg, \& Levitin, 2011), of which heavy metal is but one example. Nevertheless, in our study, we were able to show that individuals who are high in Openness show a stronger preference for tracks of contemporary heavy metal. One element of contemporary heavy metal that may make it more appealing to relatively open individuals is the use of screamed and unpitched vocals. This form of vocalization likely transfers the burden of understanding among listeners onto intrinsic qualities associated with the music, which relatively open individuals may find more challenging and, therefore, more engaging.

Our results also showed that individuals with more negative attitudes toward institutional authority were more likely to show a preference for the heavy metal tracks. In general, this is consistent with Arnett's (1993, 1996) description of heavy metal fans as inhabiting a subculture of alienation, which translates into an opposition to authority and mainstream society. The present results build on Arnett's work: It is possible, for example, that heavy metal may conjure referent images that are inherently antiauthority or that signal a revolt against mainstream culture. In this sense, individuals who hold more negative attitudes toward authority may show a preference for heavy metal precisely because it expresses their dissatisfaction with authority (see also Leung \& Kier, 2008).

Respondents who showed a stronger preference for the metal tracks in the present study were also more likely to have lower self-esteem and higher need for uniqueness. In the first instance, it is possible that individuals with relatively low self-esteem are drawn to heavy metal because the style of music allows for a purge of negative feelings. The catharsis afforded by heavy metal may, in turn, help boost self-worth and promote positive self-evaluations among those with otherwise low self-esteem (Henry \& Caldwell, 2007). In a similar vein, the demonstration of a preference for a musical genre that is outside the mainstream may help some individuals feel more unique, thus helping them to create and maintain a sense of both individual and collective uniqueness.

Two further findings of the present study are worthy of mention. First, we found that a preference for heavy metal was associated with lower religiosity. This is consistent with Arnett's (1991) finding that fans of heavy metal are significantly less religious than nongenre fans. It is possible that this association is driven by underlying attitudes toward authority, which may include religious authorities. Finally, we found that men showed a stronger preference for the tracks than women, which corroborates previous work that used video recordings of hard rock (Robinson et al., 1996). Previously work has discussed the ways in which heavy metal and related genres are used constructing, maintaining, and emphasizing masculinity and male superiority (Fast, 2005; Weinstein, 2009; see also Shank, 1994), which may help explain why this music is more appealing to men.

There are a number of important limitations with the design and implementation of our study, which need to be acknowledged. First, our sampling method possibly introduced inherent biases, which means that our final sample is unlikely to have been representative of the wider British population (the high proportion of respondents still in full-time tertiary education, e.g., speaks to this fact). In terms of design limitations, we note that we did not collect information about whether participants recognized the tracks or the artists, nor did we control for familiarity with the tracks. This is important because familiarity with a track may affect a respondents' judgment of it: Aside from the possibility of idiosyncratic preferences for certain tracks, previous exposure to a track may enhance liking for it, even if participants do not explicitly remember it (Zajonc, 1968). Conversely, overexposure to a track may decrease liking, although there appear to be important interactions between number of exposures and Openness to Experience that determine liking for musical tracks (Hunter \& Schellenberg, 2011). In addition, the correlational design of our study means that we cannot draw firm, directional conclusions. For example, it is possible that listening to heavy metal lowers self-esteem, rather than individuals with low self-esteem showing a preference for heavy metal. Finally, it is also possible that participants engaged in hypothesis guessing or provided socially desirable responses.

Aside from including a measure of familiarity with each track, there are a number of additional ways in which our study could be improved. First, our method of focusing on a particular subgenre of music should be replicated with other genres, which will help to ascertain the reliability of earlier findings based on cross-genre preferences (Delsing et al., 2008; Rentfrow \& Gosling, 2003). Indeed, our method of presenting participants with exemplar tracks of a musical subgenre may be more reliable, because it avoids possible confusion in self-reported preferences in the absence of a frame of reference. Second, future research would do well to include measures with improved validity and reliability (e.g., compared with our single-item measure of religiosity) and a wider range of individual difference traits. For example, previous studies have reported both positive (Litle \& Zuckerman, 1986; Rawlings, Vidal, \& Furnham, 2000) and null (Glasgow, Cartier, \& Wilson, 1985) associations between a preference for rock music and sensation seeking. This issue could perhaps be clarified using the methodology we have described here. In a similar vein, it may be important in future research to include measures of preference for different genres of music, listening habits, and uses of music.

These limitations notwithstanding, our study contributes to the extant literature by showing that some individuals may be drawn to heavy metal because of their personalities. That is, individuals who show a particular constellation of individual difference traits (in particular, high Openness, antiauthority attitudes, need for uniqueness, and low self-esteem) appear to show a stronger preference for contemporary heavy metal. More broadly, our results may help scholars to more fully understand why some individuals are attracted to nonmainstream music. Rather than stereotyping fans as deviant, antisocial, or violent (Wright, 2000), it may be more fruitful to understand the psychological needs that contemporary heavy metal fill for some individuals. Doing so may allow practitioners to better engage with fans of different forms of music.

\section{References}

Abdel-Khalek, A. M. (2007). Assessment of intrinsic religiosity with a single-item measure in a sample of Arab Muslims. Journal of Muslim Mental Health, 2, 211-215. doi:10.1080/15564900701614874

Arnett, J. J. (1991). Adolescents and heavy-metal music: From the mouths of metalheads. Youth \& Society, 23, 76-98. doi:10.1177/ 0044118X91023001004 
Arnett, J. J. (1993). Three profiles of heavy metal fans: A taste for sensation and a subculture of alienation. Qualitative Sociology, 16, 423-443. doi:10.1007/BF00989973

Arnett, J. J. (1995). Adolescents' uses of media for self-socialization. Journal of Youth and Adolescence, 24, 519-533. doi:10.1007/BF01537054

Arnett, J. J. (1996). Metalheads: Heavy metal music and adolescent alienation. Boulder, CA: Westview Press.

Arnett, J. J., Larson, R., \& Offer, D. (1995). Beyond effects: Adolescents as active media users. Journal of Youth and Adolescence, 24, 511-518. doi:10.1007/BF01537053

Baugh, B. (1993). Prolegomena to any aesthetics of rock music. Journal of Aesthetics and Art Criticism, 51, 23-29. doi:10.2307/431967

Berlyne, D. E. (1960). Conflict, arousal, and curiosity. New York, NY: McGraw-Hill. doi:10.1037/11164-000

Brown, C. A. (1995). Musical responses to oppression and alienation: Blues, spirituals, secular thrash, and Christian thrash metal music. International Journal of Politics, Culture, and Society, 8, 439-452. doi: 10.1007/BF02142894

Dee, L. (2009). The brutal truth: Grindcore as the extreme realism of heavy metal. In G. Bayer (Ed.), Heavy metal music in Britain (pp. 53-71). Farnham, UK: Ashgate.

Delsing, M. J. M. H., ter Bogt, T. F. M., Engels, R. C. M. E., \& Meeus, W. H. J. (2008). Adolescents' music preferences and personality characteristics. European Journal of Personality, 22, 109-130. doi:10.1002/per.665

Dollinger, S. (1993). Personality and music preference: Extraversion and excitement seeking or openness to experience? Psychology of Music, 21, 73-77. doi:10.1177/030573569302100105

Donnellan, M. B., Oswald, F. L., Baird, B. M., \& Lucas, R. E. (2006). The Mini-IPIP Scales: Tiny-yet-effective measures of the Big Five factors of personality. Psychological Assessment, 18, 192-203. doi:10.1037/10403590.18.2.192

Epstein, J. S., Pratto, D. J., \& Skipper, J. K., Jr. (1990). Teenagers, behavioral problems, and preferences for heavy metal and rap music: A case study of a southern middle school. Deviant Behavior, 11, 381-394. doi:10.1080/01639625.1990.9967860

Eysenck, H. J. (1990). Biological dimensions of personality. In L. A. Pervin (Ed.), Handbook of personality: Theory and research (pp. 244276). New York, NY: Guilford Press.

Fast, S. (2005). Led Zeppelin and the construction of masculinity. In E. Koskoff (Ed.), Music cultures in the United States (pp. 89-96). New York, NY: Routledge.

Glasgow, M. R., Cartier, A. M., \& Wilson, G. D. (1985). Conservatism, sensation seeking, and music preferences. Personality and Individual Differences, 6, 395-396. doi:10.1016/0191-8869(85)90065-0

Goldberg, L. R. (1999). A broad-bandwidth, public-domain, personality inventory measuring the lower-level facets of several five-factor models. In I. Mervielde, I. J. Deary, F. de Fruyt, \& F. Ostendorf (Eds.), Personality psychology in Europe (Vol. 7, pp. 7-28). Tilburg, The Netherlands: Tilburg University Press.

Hansen, C. H., \& Hansen, R. D. (1991). Constructing personality and social reality through music: Individual differences among fans of punk and heavy metal music. Journal of Broadcasting \& Electronic Media, 35, 335-350. doi:10.1080/08838159109364129

Henry, P., \& Caldwell, M. (2007). Headbanging as resistance or refuge: A cathartic account. Consumption, Markets, and Culture, 10, 159-174. doi:10.1080/10253860701256265

Hunter, P. G., \& Schellenberg, E. G. (2011). Interactive effects of personality and frequency of exposure on liking for music. Personality and Individual Differences, 50, 175-179. doi:10.1016/j.paid.2010.09.021

Klein, J. D., Brown, J. D., Walsh Childers, K., Oliveri, J., Porter, C., \& Dykers, C. (1993). Adolescents' risky behavior and mass media use. Pediatrics, 92, 24-31.

Kline, P. (1986). Handbook of test construction. London, UK: Routledge and Kegan Paul.
Ladinig, O., \& Schellenberg, E. G. (2012). Liking unfamiliar music: Effects of felt emotion and individual differences. Psychology of Aesthetics, Creativity, and the Arts, 6, 146-154. doi:10.1037/a0024671

Larson, R. (1995). Secrets in the bedroom: Adolescents' private use of media. Journal of Youth and Adolescence, 24, 535-550. doi:10.1007/ BF01537055

Leung, A., \& Kier, C. (2008). Music preferences and civic activism of young people. Journal of Youth Studies, 11, 445-460. doi:10.1080/ 13676260802104790

Litle, P., \& Zuckerman, M. (1986). Sensation seeking and music preferences. Personality and Individual Differences, 7, 575-578. doi:10.1016/ 0191-8869(86)90136-4

Lynn, M., \& Snyder, C. R. (2002). Uniqueness seeking. In C. R. Snyder \& S. J. Lopez (Eds.), Handbook of positive psychology (pp. 395-419). New York, NY: Oxford University Press.

McCown, W., Keiser, R., Mulhearn, S., \& Williamson, D. (1997). The role of personality and gender in preferences for exaggerated bass in music Personality and Individual Differences, 23, 543-547. doi:10.1016/ S0191-8869(97)00085-8

Mruk, C. (2006). Self-esteem research, theory, and practice: Toward a positive psychology of self-esteem (3rd ed.). New York, NY: Springer.

North, A. C., \& Hargreaves, D. J. (1999). Music and adolescent identity. Music Education Research, 1, 75-92. doi:10.1080/1461380990010107

North, A. C., Hargreaves, D. J., \& O'Neill, S. A. (2000). The importance of music to adolescents. British Journal of Educational Psychology, 70, 255-272. doi:10.1348/000709900158083

Pearson, J. L., \& Dollinger, S. J. (2002). Music preference correlates of Jungian types. Personality and Individual Differences, 36, 1005-1008.

Rana, A. (2008). Dom Kalare oss Hårdrockare: En Kultursociologisk Kartläggning av den Svenska Hårdrockspubliken [They call us metalheads: A culturo-sociological mapping of the Swedish metal scene (Unpublished master's thesis). Vaxjo University, Sweden.

Rawlings, D., Vidal, N. B., \& Furnham, A. (2000). Personality and aesthetic preference in Spain and England: Two studies relating sensation seeking and openness to experience to liking for paintings and music. European Journal of Personality, 14, 553-576. doi:10.1002/10990984(200011/12)14:6<553::AID-PER384>3.0.CO;2-H

Reicher, S., \& Emler, N. (1985). Delinquent behaviour and attitudes to formal authority. British Journal of Social Psychology, 24, 161-168. doi:10.1111/j.2044-8309.1985.tb00677.x

Rentfrow, P. J., Goldberg, L. R., \& Levitin, D. J. (2011). The structure of musical preferences: A five-factor model. Journal of Personality and Social Psychology, 100, 1139-1157. doi:10.1037/a0022406

Rentfrow, P. J., \& Gosling, S. D. (2003). The do re mi's of everyday life: The structure and personality correlates of music preferences. Journal of Personality and Social Psychology, 84, 1236-1256. doi:10.1037/00223514.84.6.1236

Rentfrow, P. J., \& Gosling, S. D. (2006). Message in a ballad: The role of music preferences in interpersonal perception. Psychological Science, 17, 236-242. doi:10.1111/j.1467-9280.2006.01691.x

Rentfrow, P. J., \& Gosling, S. D. (2007). The content and validity of music genre stereotypes among college students. Psychology of Music, 35, 306-326. doi:10.1177/0305735607070382

Rentfrow, P. J., \& McDonald, J. A. (2009). Music preferences and personality. In P. N. Juslin \& J. A. Sloboda (Eds.), Handbook of music and emotion: Theory, research, applications (pp. 669-695). New York, NY: Oxford University Press.

Robinson, T. O., Weaver, J. B., \& Zillman, D. (1996). Exploring the relation between personality and the appreciation of rock music. Psychological Reports, 78, 259-269. doi:10.2466/pr0.1996.78.1.259

Rosenberg, M. (1965). Society and the adolescent self-image. Princeton, NJ: Princeton University Press.

Rosengren, K. E., Wenner, L. A., \& Palmgreen, P. (1985). Media gratification research. Beverly Hills, CA: Sage. 
Schwartz, K. D., \& Fouts, G. T. (2003). Music preferences, personality style, and development issues of adolescents. Journal of Youth and Adolescence, 32, 205-213. doi:10.1023/A:1022547520656

Selfhout, M. H. W., Branje, S. J. T., ter Bogt, T. F. M., \& Meeus, W. H. J. (2009). The role of music preferences in early adolescents' friendship formation and stability. Journal of Adolescence, 32, 95-107. doi: 10.1016/j.adolescence.2007.11.004

Shafron, G. R., \& Karno, M. P. (2013). Heavy-metal music and emotional dysphoria among listeners. Psychology of Popular Media Culture, 2, 74-85. doi:10.1037/a0031722

Shank, B. (1994). Dissonant identities: The rock ' $n$ ' roll scene in Austin, TX. Hanover, NH: Wesleyan University Press.

Sharpe-Young, G. (2005). New wave of American heavy metal. New Plymouth, MA: Zonda Books.

Sharpe-Young, G. (2007). Metal: A definitive guide. New Plymouth, MA: Jawbone.

Snell, D., \& Hodgetts, D. (2007). Heavy metal, identity, and the social negotiation of a community of practice. Journal of Community \& Applied Social Psychology, 17, 430-445. doi:10.1002/casp.943

Snyder, C. R., \& Fromkin, H. L. (1977). Abnormality as a positive characteristic: The development and validation of a scale measuring need for uniqueness. Journal of Abnormal Psychology, 86, 518-527. doi:10.1037/0021-843X.86.5.518

Swami, V. (2012). Social psychological origins of conspiracy theories: The case of the Jewish conspiracy theory in Malaysia. Frontiers in Psychology, 3, 280. doi:10.3389/fpsyg.2012.00280

Swami, V., Chamorro-Premuzic, T., \& Furnham, A. (2010). Unanswered questions: A preliminary investigation of personality and individual difference predictors of 9/11 conspiracist beliefs. Applied Cognitive Psychology, 24, 749-761. doi:10.1002/acp.1583

Swami, V., \& Furnham, A. (in press). Personality and aesthetic experiences. In P. P. L. Tinion \& J. K. Smith (Eds.), Cambridge handbook of the psychology of aesthetics and the arts. Cambridge, UK: Cambridge University Press.

Swami, V., Pietschnig, J., Stieger, S., Nader, I. W., \& Voracek, M. (2012). Beautiful as the chance meeting on a dissecting table of a sewing machine and an umbrella! Individual differences and preferences for surrealist literature. Psychology of Aesthetics, Creativity, and the Arts, 6 , 35-42. doi:10.1037/a0024750

Swami, V., Stieger, S., Pietschnig, J., \& Voracek, M. (2010). The disinterested play of thought: Individual differences and preferences for surrealist motion pictures. Personality and Individual Differences, 48, 855-859. doi:10.1016/j.paid.2010.02.013

ter Bogt, T., Raaijmakers, Q., Vollebergh, W., van Well, F., \& Sikkema, P. (2003). Youngsters and their musical taste: Musical style and taste groups. Netherlands' Journal of Social Sciences, 39, 35-52.

Wagner, J. (2010). Mean deviation: Four decades of progressive heavy metal. New York, NY: Bazillion Points.

Waksman, P. (2009). This ain't the summer of love: Conflict and crossover in heavy metal and punk. Berkeley, CA: University of California Press.

Wallach, J., Berger, H. M., \& Greene, P. D. (2011). Affective overdrive, sense dynamics, and identity in the global metal scene. In J. Wallach, H. M. Berger, \& P. D. Greene (Eds.), Metal rules the globe: Heavy metal music around the world (pp. 3-33). Durham, NC: Duke University Press.

Weinstein, D. (2000). Heavy metal: The music and its culture. Cambridge, MA: Da Capo Press.

Weinstein, D. (2009). The empowering masculinity of British heavy metal. In G. Bayer (Ed.), Heavy metal music in Britain (pp. 17-32). Farnham, UK: Ashgate.

Weisskirch, R. S., \& Murphy, L. C. (2004). Friends, porn, and punk: Sensation seeking in personal relationships, internet activities, and music preference among college students. Adolescence, 39, 189-201.

Whiteside-Mansell, L., \& Corwyn, R. F. (2003). Mean and covariance structures analyses: An examination of the Rosenberg Self-Esteem Scale among adolescents and adults. Educational and Psychological Measurement, 63, 163-173. doi:10.1177/0013164402239323

Wright, R. (2000). "I'd sell you suicide": Pop music and moral panic in the age of Marilyn Manson. Popular Music, 19, 365-385. doi:10.1017/ S0261143000000222

Zajonc, R. B. (1968). Attitudinal effects of mere exposure. Journal of Personality and Social Psychology, 9, 1-27. doi:10.1037/h0025848

Zuckerman, M. (1979). Sensation seeking: Beyond the optimal level of arousal. Hillsdale, NJ: Erlbaum.

\section{Appendix}

Heavy Metal Bands and Tracks Used As Stimuli in the Present Study

\begin{tabular}{|c|c|c|c|c|c|}
\hline Band name & $\begin{array}{l}\text { Primary } \\
\text { classification }\end{array}$ & Track name & Album name & $\begin{array}{l}\text { Year released } \\
\text { in the U.K. }\end{array}$ & $\begin{array}{l}\text { Original track } \\
\text { length }\end{array}$ \\
\hline As I Lay Dying & Metalcore & Parallels & The Powerless Rise & 2010 & $4 \min 57 \mathrm{~s}$ \\
\hline August Burns Red & Metalcore & Empire & Leveller & 2011 & $3 \min 52 \mathrm{~s}$ \\
\hline Avantasia & Power metal & Scales of Justice & The Wicked Symphony & 2012 & $5 \min 3 s$ \\
\hline Cradle of Filth & Extreme metal & Lilith Immaculate & Darkly, Darkly, Venus Aversa & 2011 & $6 \min 12 \mathrm{~s}$ \\
\hline Disturbed & Heavy metal & Asylum & Asylum & 2010 & $4 \min 36 s$ \\
\hline Enslaved & Progressive metal & Ethica Odini & Axioma Ethica Odini & 2012 & $7 \mathrm{~min} 58 \mathrm{~s}$ \\
\hline Fair to Midland & Progressive metal & Musical Chairs & Arrows and Anchors & 2011 & $3 \min 32 s$ \\
\hline Kekal & Heavy metal & $\begin{array}{l}\text { Gestalt Principles of Matter } \\
\text { Perception }\end{array}$ & 8 & 2010 & $6 \min 5 s$ \\
\hline Overkill & Thrash metal & Endless War & Ironbound & 2010 & $5 \min 40 s$ \\
\hline Staind & Heavy metal & Eyes Wide Open & Staind & 2011 & $3 \min 30 s$ \\
\hline
\end{tabular}

Received December 10, 2012

Revision received July 16, 2013

Accepted July 17, 2013 